\title{
Columbia University
}

\section{Department of Economics \\ Discussion Paper Series}

Does Fertility Respond to Financial Incentives?

Guy Laroque

Bernard Salanié

Discussion Paper No.: 0708-15

Department of Economics

Columbia University

New York, NY 10027

May 2008 


\title{
Does Fertility Respond to Financial Incentives?
}

\author{
Guy Laroque ${ }^{1} \quad$ Bernard Salanié ${ }^{2}$
}

May 26, 2008

\footnotetext{
${ }^{1}$ CREST-INSEE and University College London.

${ }^{2}$ Columbia University and CEPR. This research benefited from the financial support of the Alliance program during a visit of Guy Laroque at Columbia University. We are grateful to Gary Becker, Didier Blanchet, Pierre-André Chiappori, Olivia Ekert-Jaffé, Philippe Février, Dominique Goux, James Heckman, Mark Killingsworth, Anne Laferrère, Steve Levitt, Annalisa Luporini, Thierry Magnac, Kevin Murphy, Laurent Toulemon, Alain Trannoy, Daniel Verger and James Walker for their comments.
} 


\begin{abstract}
There has been little empirical work evaluating the sensitivity of fertility to financial incentives at the household level. We put forward an identification strategy that relies on the fact that variation of wages induces variation in benefits and tax credits among "comparable" households. We implement this approach by estimating a discrete choice model of female participation and fertility, using individual data from the French Labor Force Survey and a fairly detailed representation of the French tax-benefit system. Our results suggest that financial incentives play a notable role in determining fertility decisions in France, both for the first and for the third child. As an example, an unconditional child benefit with a direct cost of $0.3 \%$ of GDP might raise total fertility by about 0.3 point.
\end{abstract}

JEL codes: J13, J22, H53

Keywords: population, fertility, incentives, benefits. 
Who can behold the male and female of each species, the correspondence of their parts and instincts, their passions, and whole course of life before and after generation, but must be sensible, that the propagation of the species is intended by Nature?

(Hume (1776 (2005)), Part III).

\section{Introduction}

It is natural for economists raised on the New Home Economics to presume the existence of a link between family transfers and fertility. The standard model of Becker $(1960,1991)$ and Willis (1973) implies that the demand for children depends on their cost, which in turn depends on family transfers (see for instance Cigno (1986) for a theoretical study of the impact of taxes on fertility). Yet in many countries (see Gauthier (1996)), family benefits are mostly designed as a way to ensure a minimum standard of living to families and children. There are notable exceptions: the policies towards families implemented in France at the end of the 1930s were in part based on the belief that family benefits increase fertility, and a 2004 reform explicitly mentions fertility as a concern. Sweden and Québec have also implemented pronatalist policies in the past; more recently, other countries with much more dire fertility issues such as Germany and Russia have enacted policy measures designed to bring them closer to the replacement rate.

How can we quantify the effects of financial incentives on fertility? Several approaches have been used so far (see for instance the survey of Hotz, Klerman, and Willis (1997)). A first group of studies uses panel data on countries; then the unit of observation is a given (country, year) pair. ${ }^{1}$ This line of work relies on the reasonable assumption that there is variation in family policies over time and space that is not entirely explained by the other explanatory variables. On the other hand, it suffers from the usual glaring problems of panel country regressions: arbitrary functional form assumptions and a huge

\footnotetext{
${ }^{1}$ Thus the work of Ekert-Jaffé (1986), Blanchet and Ekert-Jaffé (1994) and Gauthier and Hatzius (1997) suggests that the French family benefit system may increase total fertility by 0.1 to 0.2 child per woman.
} 
number of omitted variables whose variation must be heroically assumed to be orthogonal to the variation in policy parameters. These are compounded by the fact that these studies sum up very complex tax-benefit systems in a couple of variables only ${ }^{2}$. Thus the results obtained in these papers seem fragile.

More recent work has used individual data, which alone can provide the analyst with a large number of observations and with enough information to measure precisely financial incentives to fertility. A few recent studies have used the natural experiments approach to evaluate the fertility impact of a given family benefit. Thus Milligan (2004) studies the effect of a cash benefit given on the birth of a child in Québec in the 1990s; by comparing fertility of similar women residing in Québec and in other Canadian states over this period, it finds that this benefit strongly stimulated fertility. However, his approach cannot yield an estimate of a "price elasticity". Similar remarks apply to Kearney (2004), who estimates the fertility effect of the introduction of family caps in many US states following the 1996 reform of welfare. ${ }^{3}$ A number of papers also studied the effects of the American welfare system on fertility (see Moffitt (1998)); the results of Rosenzweig (1999) thus suggest that in the 70s, social transfers like the AFDC had a large effect on the probability that a young lower-class woman would become a single mother. Keane and Wolpin (2007b, 2007a) estimate a dynamic programming model of the decisions of young women. Their simulations suggest that the EITC, whose amount is very low for single-child families, has increased the fertility of high school dropouts by about 0.2 child per woman. Finally, Cohen, Dehejia, and Romanov (2007) exploit a drastic reduction of child allowances in Israel that affected mostly large families in 2003; their results suggest a large

\footnotetext{
${ }^{2}$ Ideally, one should also control for the endogeneity of policy variables, as argued by Heckman (1976) and more recently by Besley and Case (2000).

${ }^{3}$ There is a small body of econometric literature that aims at estimating the effect of female and male wages on fertility. Papers by Rosenzweig and Schultz (1985), Hotz and Miller (1988), Heckman and Walker (1989, 1990a, 1990b) confirm that as predicted by theory, fertility decreases with the woman's potential wage and increases with the other income of the household. The estimated effects are small; but as these papers make no attempt to use the form of the tax-benefit system, it is not quite clear what the estimated coefficients of wages represent in any case.
} 
negative impact on the fertility of poorer households and new immigrants.

This brief literature review shows that it is difficult to find reliable sources of variation and credible exclusion restrictions to identify the sensitivity of fertility to the cost of children, both for theoretical and for practical reasons. ${ }^{4}$ Section 2 presents and justifies our empirical strategy, which is based on comparing the fertility outcomes of women who have similar characteristics except for their wage and the wage of their partner. As family benefits depend on the two parents' primary incomes, this provides variation in incentives that we use to identify the relevant elasticity. We explain in Section 2 the pros and cons of such an approach to this particular problem.

We apply this idea to the case of France. We focus on French data not only because we know it well, but also because France has a rather generous and diverse family benefit system. Its cost (including tax credits) is evaluated at about $0.8 \%$ of GDP, and it comprises some unconditional, some meanstested, and some employment-tested benefits.

We set up a discrete choice model of fertility and participation decisions on the French Labor Force Surveys of 1997, 1998 and 1999. A crucial identifying tool is a fairly detailed representation of the relevant taxes and benefits. We have to account for women's participation decisions, given that they are so closely linked to their fertility choices ${ }^{5}$. In our model, every woman is characterized by her productivity, her disutility for work and her net utility for a new child. If her productivity is smaller than the minimum wage, the woman cannot take a job. Otherwise, she can take a job paid at her productivity if she wishes to do so. She then jointly decides on participation and fertility, depending on her individual characteristics.

We have had to make simplifying assumptions. Thus we reduce the complex dynamic decision process of couples to a static reduced form. We ignore

\footnotetext{
${ }^{4}$ Our previous work (Laroque and Salanié $(2004 \mathrm{a}, 2004 \mathrm{~b})$ ) in fact illustrates it. In our first attempts at studying fertility behavior, we did not give center stage to issues of identification; these earlier papers also included older women, which tended to contaminate our estimates.

${ }^{5}$ A paper by Lefebvre, Brouillette, and Felteau (1994) estimated a nested logit of fertility and participation on individual Canadian data; their results suggest that family benefits have a non-negligible impact on fertility. However, we devote much more attention to identification issues.
} 
part-time work, even though we know that the birth of a child often leads a woman to go from full-time to part-time. We also neglect child-care subsidies, which are important both in theory ${ }^{6}$ and in practice ${ }^{7}$, as taking them into account would require modeling the choice of child care mode.

We present our estimation results in section 3. They suggest that financial incentives play a notable role in determining fertility decisions in France, both for the first and for the third child. We simulate the increase in births that results from adding to the existing tax-benefit system a child subsidy of 150 euros per month. This would have a direct cost of about $0.3 \%$ of GDP ${ }^{8}$; and according to our estimates, it would raise total fertility by about 0.3 point, while reducing female labor supply by about 0.5 point.

Our paper completely skirts normative questions. Governments may subsidize fertility because they feel that current policies deter childbearing, or to "save Social Security", and of course for a host of non-economic reasons. These are beyond our horizon here. On the other hand, it would be possible to use our estimated model to analyze the redistributive effects of any reform of family benefits; we leave this for further research.

\section{$2 \quad$ Identifying Incentive Effects}

\subsection{The Statistical Problem}

Our aim here is to use data on fertility outcomes $F_{i}$, employment decisions $L_{i}$ and explanatory variables $Z_{i}$ for various observational units to infer the effect of financial incentives on fertility. Financial incentives to fertility depend on the tax-benefit-system, which we represent as a function that maps the labor supply and fertility decisions of the observation unit $F_{i}$ and $L_{i}$ into a net household income $R\left(F_{i}, L_{i}, Z_{i}\right)$ that also depends on its characteristics $Z_{i}$. Thus we want to evaluate (both ex post and ex ante) the impact of changes

\footnotetext{
${ }^{6}$ See e.g. Apps and Rees (2004).

${ }^{7}$ Blau and Robins (1989) estimate the effect of child-care costs on fertility, using geographical variation in child-care availability. See also del Boca (2002) and Choné, Leblanc, and Robert-Bobée (2004).

${ }^{8} \mathrm{We}$ take this as a reasonable upper bound on what is politically feasible.
} 
in the function $R$ on fertility outcomes. In France, the function $R$ is very complicated, highly nonlinear and not even differentiable; but at least it is public information and it can be evaluated for all values of its arguments.

It is hard to discuss identification at this level of generality; let us therefore focus on the simple setup we actually use in our application, in which an observational unit is a household at a given date, the decision variable $L_{i}=$ 0,1 is the woman's extensive margin decision of working or not, and the fertility outcome $F_{i}=0,1$ is the occurrence of a birth.

The vector of explanatory variables $Z_{i}$ may comprise several classes of variables. Since a woman at a given period is our observational unit, $Z_{i}$ may contain:

- socio-demographic variables $x_{i}$ such as education, region, past fertility, marriage status, and so on, which may impact current fertility directly or because they contribute to determining taxes and benefits;

- the market wage of this woman $w_{i}$, which we take to be her earning potential if she does not actually work;

- the actual wage income of her partner (if any), which we denote $w_{i}^{m}$.

Several of these variables are clearly not strongly exogenous: the unobserved "taste for children", for instance, probably reduces human capital investment and therefore education; and past fertility can only be weakly exogenous. We abstract from endogeneity concerns in this section since we want to focus on identification: we will assume that $Z=\left(x, w, w_{m}\right)$ is strongly exogenous. We will also assume for now that $w$ is observed for all women, whereas of course it has to be imputed for non-working women.

If a woman's labor supply decision is $L$, then her wage income $w L$ enters the $R$ function; but so does $L$ itself since some benefits are employmenttested. Thus the tax-benefit system can be described in our application by four functions which correspond to the four alternatives $L=0,1 ; F=0,1$ :

- net household income when the woman does not work and no birth occurred $R_{00}(Z)$; 
- net household income when the woman does not work and a birth occurred $R_{01}(Z)$;

- net household income when the woman works and no birth occurred $R_{10}(Z)$;

- net household income when the woman works and a birth occurred $R_{11}(Z)$.

Note that when the woman does not work, her market wage $w$ does not enter the net household income; thus $R_{00}(Z)$ and $R_{01}(Z)$ do not depend on $w$, but only on $X=\left(x, w^{m}\right)$.

Given this notation, let $Q$ be the distribution of the endogenous variables $L$ and $F$; we can write it in all generality as

$$
Q\left(L, F \mid R_{00}(X), R_{01}(X), R_{10}(Z), R_{11}(Z), Z\right)
$$

and our aim is to evaluate changes in the distribution of $F$ when any of the four functions $R_{i j}$ shifts.

In this setup, we can only identify nonparametrically from the data the distribution of $L$ and $F$ conditional on $Z$, which we denote $P(L, F \mid Z)$. Under our exogeneity assumptions, this allows us to answer questions such as:

- what is the effect of more education on fertility?

- what is the effect of higher male or female wages on fertility?

On the other hand, it does not allow us to evaluate policy-induced changes in $R$ without further non-testable restrictions.

\section{$2.2 \quad$ Identifying Assumptions}

The basic problem we face is that since there are four alternatives, we can identify nonparametrically only three functions of $Z$ from the data. But knowing $Q$ requires identifying three functions of both $Z$ and four other arguments (the $R_{i j}$ 's.) Before we discuss possible sources of exclusion restrictions, we introduce our approach to identification on the simple labor supply model. 


\subsubsection{Identifying Labor Supply Behavior}

As in our application, we focus here on the extensive margin ${ }^{9}$. In this case we observe a probability of working $P(Z)$; and our aim is "only" to recover a probability $Q\left(R_{0}(X), R_{1}(Z), Z\right)$, where $R_{1}$ (resp. $R_{0}$ ) is household net disposable income when the woman works (resp. does not work.) Here one simple way to achieve identification is to assume that

Assumption 1 The woman's market wage w only enters $Q$ through its effect on $R_{1}$ (net household income when the woman works).

Assumption 2 The wage income of her partner (if any) $w^{m}$ only enters $Q$ through its effect on $R_{1}$ and on $R_{0}$ (net household income when the woman does not work).

Recall our notation: $X=\left(x, w^{m}\right)$ and $Z=(X, w)$. Given assumptions 1 and 2, we can write $P(Z)$ as $Q\left(R_{0}(X), R_{1}(Z), x\right)$. Then changes in $w$ identify the effect of $R_{1}$ on labor supply $Q$; and changes in $w^{m}$, compensated by changes in $w$ so as to leave $R_{1}$ constant, identify the effect of $R_{0}$ on labor supply.

More formally, fix $x$ and let $\mathcal{W}_{2}(x)$ be the support of the observed distribution of $\left(w, w^{m}\right)$ given $x$. Then the effect of a change of the tax schedule $\left(R_{0}, R_{1}\right)$ into $\left(R_{0}^{\prime}, R_{1}^{\prime}\right)$ is identified as follows.

Take any $\left(w, w^{m}\right)$ such that:

- $\left(w, w^{m}\right) \in \mathcal{W}_{2}(x)$;

- there exists a solution $\left(\tilde{w}, \tilde{w}^{m}\right) \in \mathcal{W}_{2}(x)$ to

$$
\left\{\begin{array}{l}
R_{0}^{\prime}\left(w^{m}, x\right)=R_{0}\left(\tilde{w}^{m}, x\right) \\
R_{1}^{\prime}\left(w, w^{m}, x\right)=R_{1}\left(\tilde{w}, \tilde{w}^{m}, x\right) .
\end{array}\right.
$$

Then the effect of such a policy change on the labour supply of an individual with characteristics $\left(w, w^{m}\right)$ is just

$$
P\left(\tilde{w}, \tilde{w}^{m}, x\right)-P\left(w, w^{m}, x\right) .
$$

\footnotetext{
${ }^{9}$ The identification problem is similar on the intensive margin, unless of course (often implicit) assumptions are made to constrain the possible causes of variation in hours.
} 
(and under assumptions 1 and 2, it clearly does not depend on the choice of the solution $\left.\left(\tilde{w}, \tilde{w}^{m}\right)\right)$.

When the range of $\mathcal{W}_{2}(x)$ is too small, identification may be sought through further restrictions, which often involve $x$. E.g. let there be a variable $s$ that only enters $Q$ through its effect on $\left(R_{0}, R_{1}\right)$, and denote $x=(s, t)$; then for given $Z=\left(w, w^{m}, s, t\right)$, we only need to find a solution $\left(\tilde{w}, \tilde{w}^{m}, \tilde{s}\right)$ to

$$
\left\{\begin{array}{l}
R_{0}^{\prime}\left(w^{m}, s, t\right)=R_{0}\left(\tilde{w}^{m}, \tilde{s}, t\right) \\
R_{1}^{\prime}\left(w, w^{m}, s, t\right)=R_{1}\left(\tilde{w}, \tilde{w}^{m}, \tilde{s}, t\right)
\end{array}\right.
$$

in the support of the distribution of $\left(w, w^{m}, s\right)$ given $t$, and the effect of the change then is

$$
P\left(\tilde{w}, \tilde{w}^{m}, \tilde{s}, t\right)-P\left(w, w^{m}, s, t\right) .
$$

While this is enough to identify the effects of changes in taxes and benefits, we need more if we want to identify the underlying utility functions. From now on, the whole analysis is done conditional on $x$, which we drop from the notation. Let us set up a standard binomial model. Labor supply is the outcome of a utility maximization where

\section{Assumption 3}

- the utility of the woman is $U_{1}\left(R_{1}\right)-d$ when she works and her household has disposable income $R_{1}$;

- it is $U_{0}\left(R_{0}\right)$ when she does not work and her household has disposable income $R_{0}$,

where $d$ measures the random disutility of labor, unobserved by the econometrician, which has a distribution $G$ that does not depend on $w$ or $w^{m}$. Similarly, $U_{0}$ and $U_{1}$ only depend on $\left(w, w^{m}\right)$ through $R_{0}$ and $R_{1}$.

Then we can reparameterize the probability of working as $Q\left(R_{0}, R_{1}\right)$. Identification of the binomial choice model has been studied by Matzkin 
(1992); but for our purposes, the following result in the line of Manski $(1985,1988)$ is more convenient:

Theorem 1 Assume the true model satisfies Assumptions 1, 2 and 3. Moreover assume that

1. $G, U_{0}$ and $U_{1}$ are differentiable, with positive derivatives;

2. denote $\mathcal{R}_{2}$ the image of $\mathcal{W}_{2}$ by the pair of functions $\left(R_{0}, R_{1}\right)$; then $\mathcal{R}_{2}$ has a non-empty interior in $\mathbb{R}^{2}$;

3. there exists a point $\left(\tilde{r}_{0}, \tilde{r}_{1}\right)$ in $\mathcal{R}_{2}$ such that $Q\left(\tilde{r}_{0}, \tilde{r}_{1}\right)=0.5$;

4. $G(0)=0.5$.

Take any triple of functions $\left(u_{0}, u_{1}, g\right)$ that is consistent with the data generated by $\left(U_{0}, U_{1}, G\right)$. Then under these assumptions, there exist numbers a (positive) and $b$ such that for all $\left(r_{0}, r_{1}\right)$ in the interior of $\mathcal{R}_{2}$,

$$
u_{0}\left(r_{0}\right)=a U_{0}\left(r_{0}\right)+b \quad \text { and } \quad u_{1}\left(r_{1}\right)=a U_{1}\left(r_{1}\right)+b
$$

and defining the function $\delta\left(r_{0}, r_{1}\right)=u_{1}\left(r_{1}\right)-u_{0}\left(r_{0}\right)$ over $\mathcal{R}_{2}$,

$$
g(y)=Q\left(r_{0}, r_{1}\right) \text { if } y=\delta\left(r_{0}, r_{1}\right)
$$

Proof: Take $\left(r_{0}, r_{1}\right)$ inside $\mathcal{R}_{2}$. Since $G^{\prime}>0$, simple differentiation in the interior of $\mathcal{R}_{2}$ yields

$$
-\frac{\frac{\partial Q}{\partial R_{0}}}{\frac{\partial Q}{\partial R_{1}}}\left(r_{0}, r_{1}\right)=\frac{U_{0}^{\prime}\left(r_{0}\right)}{U_{1}^{\prime}\left(r_{1}\right)} .
$$

It follows that any possible $\left(u_{0}, u_{1}\right)$ must satisfy

$$
\frac{U_{0}^{\prime}\left(r_{0}\right)}{u_{0}^{\prime}\left(r_{0}\right)}=\frac{U_{1}^{\prime}\left(r_{1}\right)}{u_{1}^{\prime}\left(r_{1}\right)}=a
$$

where $a$ is constant, since it cannot depend on $r_{1}$ by the first equality, nor on $r_{0}$ by the second equality (and $a$ is positive since utilities are increasing.) 
Integrating gives

$$
\left\{\begin{array}{l}
u_{0}\left(r_{0}\right)=a U_{0}\left(r_{0}\right)+b_{0} \\
u_{1}\left(r_{1}\right)=a U_{1}\left(r_{1}\right)+b_{1} .
\end{array}\right.
$$

Moreover, $G(0)=0.5$ by assumption, so that

$$
U_{1}\left(\tilde{r}_{1}\right) \equiv U_{0}\left(\tilde{r}_{0}\right)
$$

This equality must also hold for $u_{0}$ and $u_{1}$; but $G\left(U_{1}\left(\tilde{r}_{1}\right)-U_{0}\left(\tilde{r}_{0}\right)\right)=0.5$ can also be rewritten as

$$
G\left(\frac{u_{1}\left(\tilde{r}_{1}\right)-u_{0}\left(\tilde{r}_{0}\right)}{a}-\frac{b_{1}-b_{0}}{a}\right)=0.5
$$

which implies

$$
G\left(-\frac{b_{1}-b_{0}}{a}\right)=0.5
$$

and so $b_{0}=b_{1}=b$. QED.

Note that this model has testable "nonparametric" implications:

1. $Q$ must increase in $R_{0}$ and decrease in $R_{1}$;

2. $\log \left(-Q_{0}^{\prime} / Q_{1}^{\prime}\right)$ must have a zero cross derivative.

While the first one is fairly weak, the second one may provide an informative check on the model. Recall Assumption 3: conditional on $x$, the distribution of the disutility of labor $d$ does not depend on $\left(w, w_{m}\right)$, that is, on $\left(R_{0}, R_{1}\right)$. If for instance the conditional variance of $d$ depends on $R_{0}$ and $R_{1}$ in any way, then the second restriction above will not hold. If the conditional mean of $d$ depends on $\left(R_{0}, R_{1}\right)$, tests based on the second restriction will also detect it unless this conditional mean is separably additive in $R_{0}$ and $R_{1}$.

\subsubsection{Missing Wages}

To be complete, we should recall that wages $w$ are only observed for working women. Selection may come from preference shocks or be linked to the minimum wage. The issue is akin to the treatment effect problem: to achieve nonparametric identification, we need one variable in the selection equation 
(into employment) that only enters the outcome equation (the wage equation) through its effect on the propensity score. The partner's wage $w^{m}$ (if present) can play such a role; in our specification we also use family composition variables to that effect: they figure in the disutility of work - here in $U_{1}-U_{0}-$ but not in the wage equation.

\subsubsection{Identifying Fertility Behavior}

For the more complicated case of joint fertility-participation behavior, such restrictions will not suffice. Pursuing the strategy in section 2.2.1, we would start by assuming that $w$ only enters $Q$ through $R_{10}$ and $R_{11}$ and that $w^{m}$ only enters $Q$ through the $R_{i j}$ 's. Then we would want to identify the change from $\left(R_{00}, R_{01}, R_{10}, R_{11}\right)$ to $\left(R_{00}^{\prime}, R_{01}^{\prime}, R_{10}^{\prime}, R_{11}^{\prime}\right)$ on a woman $\left(w, w^{m}, x\right)$ by solving a system of equations of the form

$$
\left\{\begin{array}{l}
R_{00}^{\prime}\left(w^{m}, x\right)=R_{00}\left(\tilde{w}^{m}, \tilde{x}\right) \\
R_{01}^{\prime}\left(w^{m}, x\right)=R_{01}\left(\tilde{w}^{m}, \tilde{x}\right) \\
R_{10}^{\prime}\left(w, w^{m}, x\right)=R_{10}\left(\tilde{w}, \tilde{w}^{m}, \tilde{x}\right) \\
R_{11}^{\prime}\left(w, w^{m}, x\right)=R_{11}\left(\tilde{w}, \tilde{w}^{m}, \tilde{x}\right) .
\end{array}\right.
$$

Since we have four equations, this can only work if we can find a subset $s$ of the variables in $x$ that only enters $Q$ through the $R_{i j}$ 's; and the dimension of $s$ must be at least two. This is not a very appealing strategy: we can make a reasonable case for excluding some variables from the disutility of labor or the utility of income, but it is much harder for the costs and benefits of children.

A possible source for such variation in $s$ is policy reforms that change the net cost of children, preferably in different ways for different types of households. As an example, the recent rebound in fertility in France (see figure 1) has sometimes been linked in the media with various family policy measures which date from the same period, particularly with the extension of the "Allocation Parentale d'Éducation" to the second-born in 1994. Piketty (2005) attempted to evaluate the consequences of this reform on fertility; he concludes that they are very hard to isolate, but that the 1994 reform cannot 


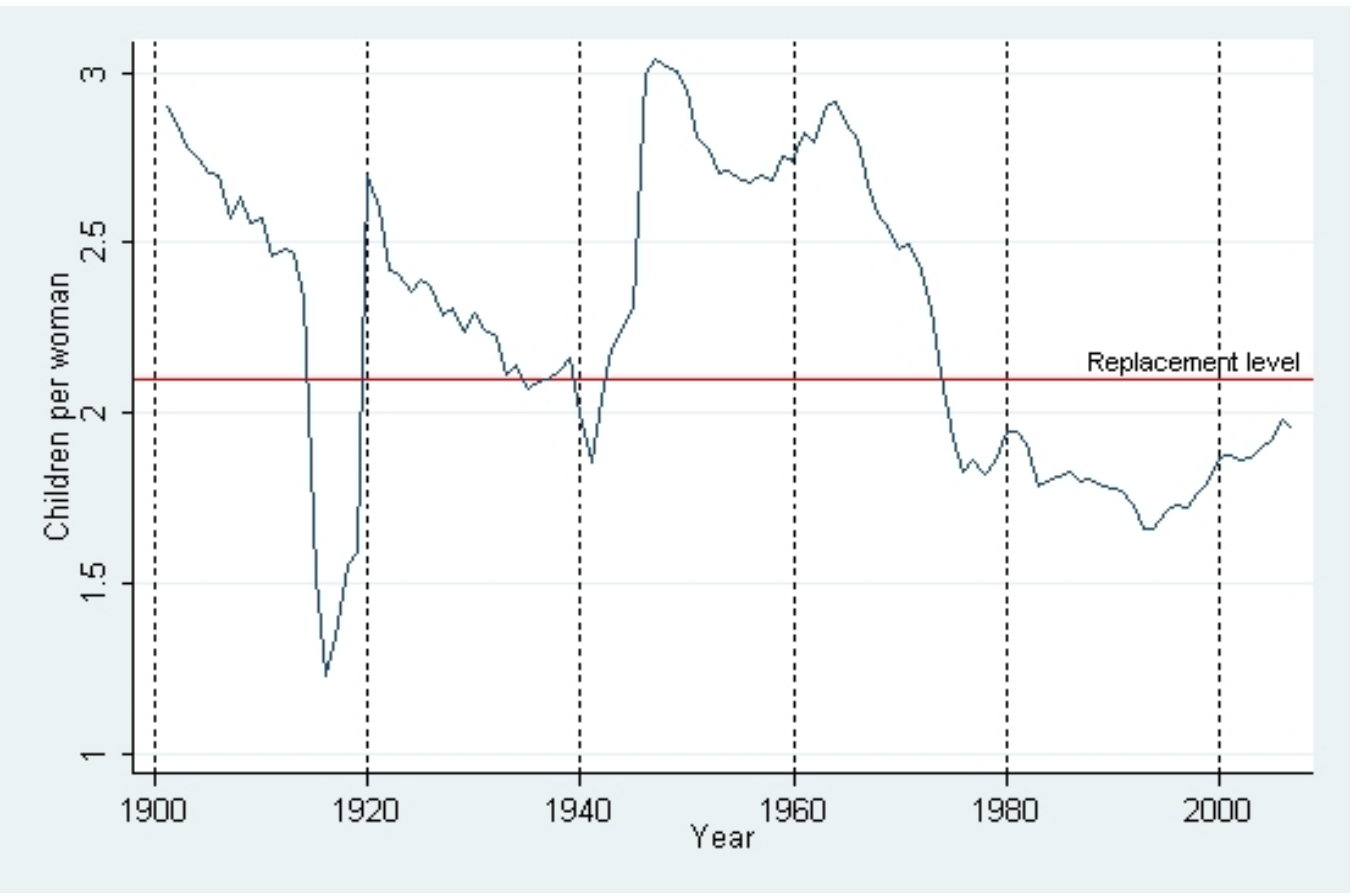

Figure 1: Children per woman from 1901 to 2007

account for more than 20-30\% of the observed increase in births.

We adopt a quite different approach: we resort to structural restrictions, which hopefully only act as identifying constraints. Again, we condition on $x$, and we drop it from the notation. We study the decision to work or not $(L=1,0)$, with a newborn child or not $(F=1,0)$. The choice among the four $(L, F)$ pairs is derived from utility maximizing, where the utilities are given by

$$
\begin{aligned}
& \mathcal{U}_{00}=U_{00}\left(R_{00}\right) \\
& \mathcal{U}_{01}=U_{01}\left(R_{01}\right)-c_{1} \\
& \mathcal{U}_{10}=U_{10}\left(R_{10}\right)-\zeta_{10} \\
& \mathcal{U}_{11}=U_{11}\left(R_{11}\right)-c_{1}-\zeta_{11} .
\end{aligned}
$$

Given biological constraints, decisions are taken sequentially: a woman decides on her fertility, then, given realized family composition, on her participation. The solution, as in dynamic programming, is computed backwards: 
first one compares $\mathcal{U}_{0 F}$ and $\mathcal{U}_{1 F}$ for a given value of $F=0,1$, then the expected values of $\max \left(\mathcal{U}_{0 F}, \mathcal{U}_{1 F}\right)$ to choose the optimal $F$.

The utility indices $U_{L F}$ are deterministic functions of household incomes, which are assumed to be perfectly anticipated. Without loss of generality, we take 00 to be the reference situation for which the disturbance is normalized to zero. The other random terms are written in such a way that $\zeta_{10}$ and $\zeta_{11}$ represent the labor supply disturbances in the second stage, given realized fertility, while $c_{1}$ represents a shock on the cost of a newborn child. It is convenient to assume that the three terms $\left(\zeta_{10}, \zeta_{11}, c_{1}\right)$ are mutually independent. ${ }^{10}$

\section{Assumption 4}

- the women anticipate perfectly their own wage as well as the wage of their partner;

- the shocks on the disutilities of labor given the presence of a newborn or not, $\zeta_{10}$ and $\zeta_{11}$, and the shock on the cost of a child $c_{1}$ are independently distributed.

We denote $G_{0}$ (resp. $G_{1}$ ) the unknown distribution of $\zeta_{10}$ (resp. $\zeta_{11}$ ), and $K$ the unknown distribution of $c_{1}$. It turns out that these assumptions are (almost) enough to identify the true utility functions $U_{00}, U_{01}, U_{10}$ and $U_{11}$ and the distributions $G_{0}, G_{1}$ and $K$ up to the usual scale and location normalization.

First consider labour supply decisions given the realization of the "newborn" variable $F$ for a woman of characteristics $\left(w, w^{m}\right)$. Given the realization of $F$, the woman decides to work iff $\mathcal{U}_{1 F}>\mathcal{U}_{0 F}$. So she works with probability

$$
P_{F}\left(w, w^{m}\right)=G_{F}\left(U_{1 F}\left(R_{1 F}\left(w, w^{m}\right)\right)-U_{0 F}\left(R_{0 F}\left(w^{m}\right)\right)\right) .
$$

This is of course the same problem as in section 2.2.1: a nice simplification from our choice of stochastic specification is that $c_{1}$ cancels out in the labour

\footnotetext{
${ }^{10}$ In fact we only need to assume that the couple $\left(\zeta_{11}, c_{1}\right)$ is independent of $\zeta_{10}$. But it would be messier since then we have to use the distribution of $\zeta_{11}$ conditional on $c_{1}$ when describing the labor supply decision after a birth.
} 
supply decision problem. Reparameterize $P_{F}\left(w, w^{m}\right)$ as $Q_{F}\left(R_{0 F}, R_{1 F}\right)$ as before. Then we can apply Theorem 1, adapted to the new notation, for given $F=0,1$.

Theorem 2 Assume that the true model satisfies assumptions 1 to 4, and in addition:

1. $G_{F}, U_{0 F}$ and $U_{1 F}$ are strictly increasing and differentiable;

2. $G_{F}(0)=0.5$;

3. the support $\mathcal{R}_{2 F}$ of the distribution of $\left(R_{0 F}\left(w^{m}\right), R_{1 F}\left(w, w^{m}\right)\right)$ has a non-empty interior;

4. it contains a $\left(\tilde{r}_{0 F}, \tilde{r}_{1 F}\right)$ such that $U_{1 F}\left(\tilde{r}_{1 F}\right)=U_{0 F}\left(\tilde{r}_{0 F}\right)$;

then the utility functions are identified up to scale and location. More precisely, for any representation $\left(g_{F}, u_{L F}\right)$ consistent with the data, there exist numbers $a_{F}$ (positive) and $b_{F}$ such that for all $\left(r_{0}, r_{1}\right) \in \mathcal{R}_{2 F}$,

$$
u_{0 F}\left(r_{0}\right)=a_{F} U_{0 F}\left(r_{0}\right)+b_{F} \quad \text { and } \quad u_{1 F}\left(r_{1}\right)=a_{F} U_{1 F}\left(r_{1}\right)+b_{F} ;
$$

and defining the functions $\delta_{F}\left(r_{0 F}, r_{1 F}\right)=u_{1}\left(r_{1 F}\right)-u_{0}\left(r_{0 F}\right)$ over $\mathcal{R}_{2 F}$, we have

$$
g_{F}(y)=Q_{F}\left(r_{0 F}, r_{1 F}\right) \text { if } y=\delta_{F}\left(r_{0 F}, r_{1 F}\right) .
$$

Note that this implies that on the range of $\delta_{F}, g_{F}(y)=G_{F}\left(y / a_{F}\right)$.

Thus labor supply decisions in themselves give us some information about utility functions; but this is not enough to allow us to identify incentive effects of the $R$ functions on fertility: changes in the ratio $a_{1} / a_{0}$ and in the cdf of the cost of children $c_{1}$, on which we know nothing as yet, can give totally different estimates of the effect of fertility incentives.

To identify these remaining parameters, we of course need to study fertility decisions. Nature comes to our help, in that fertility decisions must be made in advance. The true indirect utility of a fertility decision $F=0,1$ is

$$
\operatorname{Emax}\left(U_{0 F}\left(R_{0 F}\left(w^{m}\right)\right), U_{1 F}\left(R_{1 F}\left(w, w^{m}\right)\right)-\zeta_{1 F}\right)-c_{F}
$$


where the expectation is only taken over the true cdf $G_{F}$ of the shock $\zeta_{1 F}$, whose value is known to the woman at the time she takes her fertility decision (and we normalized $c_{0}=0$.) Denote $V_{F}$ the expectation term in this formula. Now for any variable $\xi$ with cdf $S$, denote

$$
H(S, \alpha, \beta)=E_{\xi} \max (\alpha-\xi, \beta) .
$$

Then we can write

$$
V_{F}=H\left(G_{F}, U_{1 F}\left(R_{1 F}\right), U_{0 F}\left(R_{0 F}\right)\right) .
$$

Therefore the probability of a newborn $F=1$ is

$$
P=\operatorname{Pr}\left(V_{1}-c_{1}>V_{0}\right)=K\left(V_{1}-V_{0}\right) \equiv K(\Omega),
$$

with

$$
\begin{aligned}
\Omega\left(w, w^{m}\right)=H\left(G_{1}, U_{11}\left(R_{11}\left(w, w^{m}\right)\right), U_{01}\left(R_{01}(w)\right)\right) & \\
& -H\left(G_{0}, U_{10}\left(R_{10}\left(w, w^{m}\right)\right), U_{00}\left(R_{00}(w)\right)\right) .
\end{aligned}
$$

Labour supply data yield a representation $\left(g_{F}, u_{L F}\right)$ equal to the true one $\left(G_{F}, U_{L F}\right)$ up to an intercept $b_{F}$ and a scale factor $a_{F}$ :

$$
\left\{\begin{array}{l}
u_{L F}(y) \equiv a_{F} U_{L F}(y)+b_{F} \\
g_{F}\left(a_{F} y\right) \equiv G_{F}(y) .
\end{array}\right.
$$

Any such choice of $\left(a_{0}, a_{1}, b_{0}, b_{1}\right)$ generates its own representation of $\Omega$, call it $\omega$. The data gives us the probability $P\left(w, w^{m}\right)$ that a woman has a baby, conditional on her wage and her partner's. We must still solve the functional equation

$$
P\left(w, w^{m}\right) \equiv k\left(\omega\left(w, w^{m}\right)\right)
$$

with unknowns $k,\left(a_{0}, a_{1}\right)$, and $\left(b_{0}, b_{1}\right)$.

To go further, we need some regularity assumptions. We first need to 
define an "expected marginal rate of substitution" for $F=0,1$ :

$$
M_{F}\left(w, w^{m}\right)=\frac{\frac{\partial V_{F}}{\partial w}}{\frac{\partial V_{F}}{\partial w^{m}}}\left(w, w^{m}\right)
$$

We now state

Assumption 5 There exists $\left(\tilde{w}, \tilde{w}^{m}\right)$ in the interior of $\mathcal{W}_{2}$ such that $M_{0}\left(\tilde{w}, \tilde{w}^{m}\right) \neq$ $M_{1}\left(\tilde{w}, \tilde{w}^{m}\right)$.

Assumption 5 is very weak. It only requires that in expected terms (over the shocks on the disutility of labor $\zeta_{10}$ and $\zeta_{11}$ ), the birth of a child changes the utility value of an increase in the woman's potential wage, relative to an increase in her partner's wage. There are several reasons why we expect this to hold, with $M_{0}<M_{1}$ in fact for most values of $\left(w, w^{m}\right)$. Let us just mention two:

- since women spend more time with young children than men, an increase in their wage-earning potential is (relatively) less valuable if $F=1$ since a birth reduces participation;

- some very significant family benefits, such as the APE in France, are much more attractive for low earners.

Note that this assumption is testable: in fact, given utility functions $u_{L F}$ obtained after estimating labor supply, and estimates $P_{F}(Z)$ of the probability of working after fertility outcome $F=0,1$, the marginal utility of a wage increase is just the average of the marginal utilities when working and when not working, weighted by the corresponding probabilities ${ }^{11}$ which can be directly estimated from the data. Thus for $t=w$ or $t=w^{m}$, we can write:

$$
\frac{\partial v_{F}}{\partial t}=P_{F} \frac{\partial u_{1 F}}{\partial t}+\left(1-P_{F}\right) \frac{\partial u_{0 F}}{\partial t}
$$

and this is enough to estimate $M_{F}$ since the derivatives of $U_{L F}$ are equal to those of $u_{L F}$, known up to a scale factor $a_{F}$ which cancels out in the ratio. We will present estimates of $M_{0}$ and $M_{1}$ later on.

\footnotetext{
${ }^{11}$ Given our assumptions, no woman is ever at the margin of participation.
} 
We can now state

Theorem 3 Let all assumptions of Theorem 2 hold, along with Assumption 5. Avvvssume in addition that:

1. $K$ is differentiable and strictly increasing at $A\left(\tilde{w}, \tilde{w}^{m}\right)$;

2. the $R_{L F}$ functions are differentiable at $\left(\tilde{w}, \tilde{w}^{m}\right)$.

Then

1. the marginal utilities are identified locally up to a common scale parameter. More precisely, any representation $u_{L F}$ consistent with the data must satisfy

$$
u_{L F}^{\prime}\left(R_{L F}\left(w, w^{m}\right)\right)=\lambda U_{L F}^{\prime}\left(R_{L F}\left(w, w^{m}\right)\right)
$$

over $\mathcal{W}_{2}$ for some $\lambda>0$

2. the cdfs of $\zeta_{10}, \zeta_{11}$ and $c_{1}$ are also identified up to the choice of $\lambda$ : any representation $\left(G_{0}, G_{1}, K\right)$ consistent with the data must satisfy locally

$$
\left\{\begin{array}{l}
g_{F}(y)=G_{F}(y / \lambda) \quad \text { for } \quad F=0,1 \\
k(y)=K(y / \lambda) .
\end{array}\right.
$$

3. as a consequence, fertility effects of the tax-benefit system are exactly identified at every point of $\mathcal{W}_{2}$.

Proof: under these assumptions, let $\left(u_{L F}\right),\left(a_{F}\right),\left(b_{F}\right),\left(g_{F}\right)$ be a representation compatible with the labour supply data. Now use $(V)$ to define for $Z=\left(w, w^{m}\right) \in \mathcal{W}_{2}$, and denoting again $t=w$ or $t=w^{m}$ :

$$
\frac{\partial v_{F}}{\partial t}(Z)=P_{F}(Z) \frac{\partial u_{1 F}}{\partial t}+\left(1-P_{F}(Z)\right) \frac{\partial u_{0 F}}{\partial t} ;
$$

Clearly,

$$
\frac{\partial v_{F}}{\partial t}=a_{F} \frac{\partial V_{F}}{\partial t} .
$$


Now we can write

$$
\frac{\partial P}{\partial t}=K^{\prime}\left(K^{-1}(P)\right)\left(\frac{\partial V_{1}}{\partial t}-\frac{\partial V_{0}}{\partial t}\right) \quad(Q) .
$$

It follows that

$$
\frac{\frac{\partial P}{\partial w}}{\frac{\partial P}{\partial w^{m}}}=\frac{\frac{\partial V_{1}}{\partial w}-\frac{\partial V_{0}}{\partial w}}{\frac{\partial V_{1}}{\partial w^{m}}-\frac{\partial V_{0}}{\partial w^{m}}},
$$

or, with the alternative representation of the indirect utilities,

$$
\frac{\frac{\partial P}{\partial w}}{\frac{\partial P}{\partial w^{m}}}=\frac{\frac{\partial v_{1}}{\partial w}-\frac{a_{1}}{a_{0}} \frac{\partial v_{0}}{\partial w}}{\frac{\partial v_{1}}{\partial w^{m}}-\frac{a_{1}}{a_{0}} \frac{\partial v_{0}}{\partial w^{m}}} .
$$

This can be rearranged into

$$
\frac{a_{1}}{a_{0}}\left(\frac{\partial v_{0}}{\partial w^{m}} \frac{\partial P}{\partial w}-\frac{\partial v_{0}}{\partial w} \frac{\partial P}{\partial w^{m}}\right)=\frac{\partial v_{1}}{\partial w} \frac{\partial P}{\partial w^{m}}-\frac{\partial v_{1}}{\partial w^{m}} \frac{\partial P}{\partial w} .
$$

Everything in this equation is known at this stage, except for the ratio $a_{1} / a_{0}$. So it determines this ratio uniquely, provided that the term that multiplies it is not zero in some $t$. But if this term were zero, then so would the term on the right-hand side; and simple algebra shows that then both $M_{0}$ and $M_{1}$ would be equal to the marginal rate of substitution of $P$. Taking $Z=\left(\tilde{w}, \tilde{w}^{m}\right)$ shows that $\frac{a_{1}}{a_{0}}$ is identified since by assumption $5, M_{0} \neq M_{1}$ in this point at least.

Now fix $a_{0}=\lambda>0$, which determines $a_{1}$ and fixes $v_{0}$ and $v_{1}$; and take any $Z \in \mathcal{W}_{2}$. Equation $(Q)$ directly gives the density of $k$ at $k^{-1}(P(t))=$ $v_{1}(t)-v_{0}(t)$. Now suppose we change the tax-benefit system so that $R_{L F}$ becomes $R_{L F}+d R_{L F}$; then the probability of a birth changes by

$$
\begin{aligned}
d P=k^{\prime}\left(k^{-1}(P)\right)\left(\frac{\partial v_{1}}{\partial R_{01}} d R_{01}+\frac{\partial v_{1}}{\partial R_{11}} d R_{11}\right. & \\
& \left.-\frac{\partial v_{0}}{\partial R_{00}} d R_{00}-\frac{\partial v_{0}}{\partial R_{10}} d R_{10}\right) ;
\end{aligned}
$$

but everything in this formula is identified since, e.g.,

$$
\frac{\partial v_{1}}{\partial R_{01}}=\left(1-P_{F}\right) \frac{\partial u_{01}}{\partial R_{01}}
$$

It is easy to see that a different choice of $\lambda$ would just rescale $k^{\prime}$ and the $u_{L F}$ 's in opposite directions, QED. 


\subsection{Implementing our Approach}

In our application, we use as endogenous variables in the survey of year $t$ :

- for $F=0,1$, the occurrence of a birth between surveys $(t-1)$ and $t$

- for $L=0,1$, employment in the current month in survey $t$.

We assume that when making her fertility decision at date $(t-1)$, the woman anticipates her (potential) market wage $w_{t}$ perfectly, as well as the employment and wage of the partner $w_{t}^{m}$ and the other characteristics of her household $x_{t}$.

We found that we needed a large number of covariates $x$ to control for fertility decisions, with parity-specific fertility equations, age of the woman, ages of existing children... This makes it infeasible to go beyond parametric methods given the available data, even though the structure of our model and the continuous nature of the key variables $R_{L F}, w, w^{m}$ naturally suggests using an average derivative estimation method. ADE would seem more practical for labor supply decisions conditional on fertility, since we need fewer covariates there. But

- we also want to use observations for which $w^{m}=0$, which would require adapting the ADE method;

- more importantly, we also need to account both for the minimum wage and for missing wages.

On the other hand, we can validate the assumptions that underlie our identification of fertility responses. We shall use the $u_{L F}$ obtained at the first stage to estimate $V_{F}$ up to the scale factors $a_{F}$. This allows us first to compute the expected marginal rates of substitution $M_{0}$ and $M_{1}$ and to check that they differ from each other. Moreover, formula (K) implies that

$$
\ln \left(-\frac{\frac{\partial Q}{\partial V_{1}}}{\frac{\partial Q}{\partial V_{0}}}\right) \quad \text { has a zero cross-derivative in }\left(V_{0}, V_{1}\right)
$$


Our specification amounts to writing

$$
Q=L\left(\alpha_{1} V_{1}-\alpha_{0} V_{0}-\beta\right)
$$

where $L$ is a given cdf and $\alpha_{F}$ and $\beta$ are linear functions of coefficients and covariates. This satisfies the zero cross-derivative property by construction. To test it, we extend the specification by including quadratic terms. Denote $T$ the argument of $L$ above; we estimate

$$
Q=L\left(\gamma_{1} T+\gamma_{2} T^{2}+\gamma_{3} V_{1}^{2}+\gamma_{4} V_{0} V_{1}\right)
$$

and we test that $\gamma_{3}=\gamma_{4}=0$. This is similar to the test of the index assumption in Ichimura and Taber (2002).

\section{Specification and estimation results}

\subsection{Data and specification}

The model is estimated on data from the French labor force surveys of 1997, 1998 and 1999. We discard women who are civil servants, who are over forty years old, or who finished their studies less than two years before they were surveyed $^{12}$.

We decided to only keep women who were born French. Immigrant women (defined by being born non-French and outside of France) represent about 9\% of fertile-age women in France, but $13 \%$ of births each year are to an immigrant mother. This higher fertility is partly due to a different age profile of immigrant women, and also to births being delayed until the wife of an immigrant worker comes to live in France. Women who immigrated to France before puberty in fact have very similar fertility to French-born women. Thus the fertility of immigrant women has quite different determinants than that of French-born women.

Furthermore, in the results that are shown below, we only consider births

\footnotetext{
${ }^{12}$ The latter is to avoid modeling the decision of pursuing studies or going into the labor force.
} 


\begin{tabular}{|c|c|c|c|}
\hline $\begin{array}{c}\text { Fertility } \\
\text { Employment }\end{array}$ & 0 & 1 & Total \\
\hline 0 & 6,844 & 1,751 & 8,595 \\
1 & 7,430 & 866 & 8,296 \\
\hline Total & 14,274 & 2,617 & 16,891 \\
\hline
\end{tabular}

Table 1: The sample structure

of parity 1, 2 or 3, and women who live with a partner. Just as for immigrant women, the behavior of both large families and single parent families is significantly different, and elucidating it would require another paper. This leaves us with a sample of 16,891 observations, whose distribution into employment and fertility status is as in Table 1.

Our method relies heavily on the variation in financial incentives induced by variation in wages $w$ and $w^{m}$. Is there enough such variation in our dataset? A simple way to measure it is to define three measures of fertility incentives as

$$
\left\{\begin{array}{l}
E_{1}\left(w_{m}\right)=R_{01}\left(w_{m}\right)-R_{00}\left(w_{m}\right) \\
E_{2}\left(w, w_{m}\right)=R_{01}\left(w_{m}\right)-R_{10}\left(w, w_{m}\right) \\
E_{3}\left(w, w_{m}\right)=R_{11}\left(w, w_{m}\right)-R_{10}\left(w, w_{m}\right)
\end{array}\right.
$$

Thus $E_{1}$ refers to a woman who does not work before or after a birth, $E_{2}$ to a woman who stops working, and $E_{3}$ to a woman who works before and after. Then we regress employment, $w$ and $w_{m}$ on all explanatory variables; we simulate the estimated equations to generate the three incentive measures in the absence of idiosyncratic shocks. The results in Table 2 show that shocks to wages account for a large proportion of the variance in the $E_{i}$ 's across households, which buttresses our approach to identification.

The number of observations with a newborn child $(2,617)$ is fairly small. Therefore we shall have to be parsimonious when specifying the labor supply of women who had a baby in the past year.

We take a basic linear specification with normal and logistic disturbances, 
Table 2: Breaking down the variance in incentives

\begin{tabular}{|l|r|r|r|r|}
\hline Incentive measure & Standard error (euros/month) & Exogenous & $w$ & $w_{m}$ \\
\hline$E_{1}$ & 270 & $88 \%$ & $0 \%$ & $12 \%$ \\
$E_{2}$ & 1,000 & $47 \%$ & $51 \%$ & $2 \%$ \\
$E_{3}$ & 90 & $45 \%$ & $24 \%$ & $31 \%$ \\
\hline
\end{tabular}

from which we shall experiment with variants. The first ingredient in the specification is the utility when working or not. It is assumed to be a linear function of disposable income, and we take the disturbances affecting the disutility of work and the preference for children to be normally distributed:

$$
\begin{aligned}
u_{0 F}\left(R_{0 F}\left(w^{m}\right)\right) & =\left(\mu_{F}-\nu_{F}\right) R_{0 F}\left(w^{m}\right) \\
u_{1 F}\left(R_{1 F}\left(w, w^{m}\right)\right) & =\mu_{F} R_{1 F}\left(w, w^{m}\right)+\pi_{F}+\varepsilon_{L},
\end{aligned}
$$

where $\varepsilon_{L}$ is a centered standard normal, and $\mu_{F}, \nu_{F}$ and $\pi_{F}$ depend on a number of agents' characteristics, in particular on the presence $(F=1)$ or not $(F=0)$ of a newborn in the household. Disposable income is computed from wages and detailed features of the household through routines that approximate the French tax and benefit system. The expected utility of work then is

$$
V_{F}=\frac{1}{\mu_{F}} E \max \left[u_{0 F}, u_{1 F}\right],
$$

where the expectation is taken with respect to the shock $\varepsilon_{L}$, and we have normalized to measure utility in monetary units $^{13}$. The probability of having a child is taken as a logistic:

$$
Q=\frac{1}{1+\exp (-Y \theta)}
$$

where we have three different parameterizations for parity 1, 2 and 3, depend-

\footnotetext{
${ }^{13}$ The practical computation of $V_{F}$ follows simply from the equality
}

$$
\operatorname{Emax}(x-\varepsilon, 0)=x \Phi(x)+\phi(x),
$$

when $\varepsilon$ is a standard centered normal, with cdf $\Phi$ and pdf $\phi$. 
ing on age in a flexible way. The variables in $Y$ include the difference $V_{1}-V_{0}$ between the labor market utility indices with and without a newborn, as well as the level $V_{0}$, both interacted with age and diploma. On top of these financial incentives variables, we have age, by itself and interacted with diploma and being legally married. For parity two and three, the composition of the family enters and is also interacted with the financial variables.

All parameters are estimated by maximum likelihood, with the endogenous variable being the couple $(L, F)$. In the basic version of the model, there are 136 parameters to estimate. The estimation program is written in $\mathrm{R}$ and the optimization takes a couple of hours.

Remark: A complication comes from the fact that the value of the woman labor cost $w$ is only observed by the econometrician for those women who participate. We handle this issue as follows. We maintain the assumption that every woman knows her potential wage $w$, and chooses her decisions accordingly. But the econometrician does not know $w$ for the non participating women. Then the econometrician postulates and estimates a model for wages, and uses it to take the expectation of the likelihood of the woman's decision. Following standard practice, we posit a Mincer equation for the employer wage cost $w$ :

$$
\log w=X \beta+\sigma \varepsilon_{w}
$$

where $X$ includes age at end of studies, time spent since end of studies and their squares, as well as highest diploma obtained in five categories. We estimate the Mincer equation in a first stage. To do this, we estimate a participation model with exogenous fertility; we follow a procedure close to Laroque and Salanié (2002) to take into account the existence of a (high) minimum wage which bars a number of low skilled women from employment. The results presented below take the Mincer equation as given, and in particular do not correct standard errors for the pre-estimation stage. 


\subsection{Estimation results}

All the tables are gathered at the end of the paper. Incomes are measured in hundreds of euros. To fix ideas, the median monthly household income in our sample (as measured by the observed value of $R_{L F}$ ) is 1,950 euros.

\subsubsection{Labor supply}

We specify and estimate in a flexible way the utilities of working from (3), which are identified through the choice of a standard normal disturbance.

The coefficients of $\mu_{F}$, which measures the sensitivity of the labor supply of women to financial incentives to work $\left(R_{1 F}-R_{0 F}\right)$, are shown in Table 5 . For women without babies, who are in relatively larger number, $\mu_{0}$ is represented as the sum of indicator functions, of annual age, of college education and of the size of the family (parity 2 or 3 ). To interpret the magnitude of the coefficients, one must bear in mind the fact that on average half of the women of the sample work: the shape of the normal distribution implies that at the average point a change of 0.1 in the deterministic utility $u_{1 F}-u_{0 F}$ corresponds to a change of 4 points in the probability of working.

The sensitivity to financial incentives seems to be slightly decreasing with age, from around 0.27 to 0.20 for a low skilled woman without children (Table 5). An increase of 100 euros in the monthly income of such a household would increases the woman's probability of working by approximately 10 points. The sensitivity to incentives is slightly lower for educated women and/or for women with two children, as $a_{0}$ is reduced by .04 in both cases.

Given that only $15 \%$ of women in our sample have a baby in a given year, we specify $\mu_{1}$ as the sum of $\mu_{0}$, a linear function of age, and an indicator of a family with two children. The age term is insignificant, but the mean estimate of these additional terms is negative; this suggests that the labor supply of women with a newborn is less sensitive to financial incentives. On the other hand, having two children increases $\mu_{1}-\mu_{0}$ by 0.08 : so after the birth of a third child women are more sensitive to financial incentives.

The coefficient $\nu_{F}$ measures the income effects on labor supply and is presented in Table 6. Leisure is a normal good for women without children: 
an increase of 100 euros per month of other income (i.e. of her husband income) reduces their probability of working by 4 points on average. The effect is reversed for women with a baby, as already seen in Laroque and Salanié (2002): one interpretation is that having a husband with a larger income allows the woman to hire child care and continue with her professional career. Indeed for a second born, an increase of other income of 100 euros per month increases the probability of getting a job by 7 points on average.

Finally the coefficient $\pi_{F}$ describes the constant term. For flexibility, $\pi_{0}$ is represented as the sum of indicator functions, of age dummies, of diplomas and of household structure (see Table 7). The constant is modified for women with a young baby, by adding a quadratic polynomial in age, with three indicators of education and family structure. The results are by and large unsurprising: ${ }^{14}$ high diplomas make women more likely to work, having two children and/or a baby deters from work.

Given the estimated utility functions, we can compute the "expected marginal rates of substitution" $M_{F}$, equal to $\left(\partial \bar{V}_{F} / \partial w\right) /\left(\partial \bar{V}_{F} / \partial w^{m}\right)$, for each observation of our sample. Figure 2 plots $M_{1}$ against $M_{0}$ for parities 0,1 and 2. Our identifying assumption 5 only requires that the points do not cluster too close to the diagonal, conditional on the exogenous variables that affect fertility. The graphs above prove that $M_{0}$ and $M_{1}$ are rather different for a large subset of values of $x$. Moreover, the great majority of observations has $M_{0}>M_{1}$ as expected. Of course, the only way to check that we have enough variation for identification is to estimate the fertility model.

\subsubsection{Fertility decisions}

As already mentioned, fertility is specified as a logit, and the specification and coefficients differ across parities. The results are presented in Tables 8, 9 and 10 respectively for parities 1, 2 and 3 .

\footnotetext{
${ }^{14}$ The only unusual sign is the negative one that appears in front of the 'unmarried' indicators. Women living with a partner, without being legally married, appear to have a lower labor supply, all other things equal. We do not have a ready explanation for this result.
} 


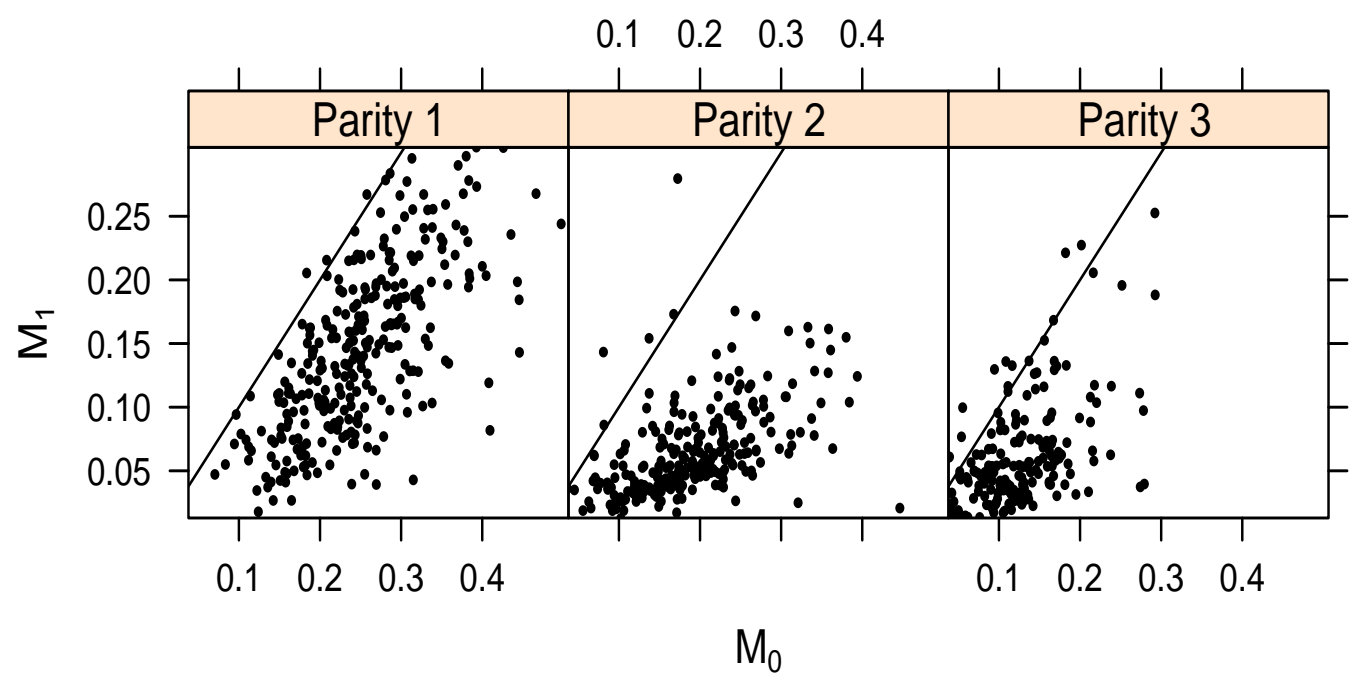

Figure 2: Scatter plots of $M_{1}$ against $M_{0}$

The main variable of interest is the difference of the expected utilities when having a baby or not, $\left(V_{1}-V_{0}\right)$. This variable is interacted with age education and family composition, but since $15 \%$ of the women in the sample have a baby, we do not have enough degrees of freedom to use a full set of age dummies. Instead we posit a spline function of age, with three knots located at the $15 \%, 50 \%$ and $85 \%$ quantiles of the age distribution of the sample for each parity.

We renormalized the estimated utility indices $V_{F}$ so that they can be interpreted in hundreds of euros per month. Thus given the functional form of the logit, a change of 100 euros per month in $\left(V_{1}-V_{0}\right)$ changes the probability $Q$ of fertility by $Q(1-Q) \theta$, where $\theta$ is the coefficient of $\Delta V$ that appears in the tables. Take for example the change in $Q$ for an average 24 year old woman without children associated with an increase of financial incentives of 100 euros. Since $Q$ is equal to 0.17 on average for these women, the increase in the probability of a birth is $0.17 \times 0.83 \times 0.21=0.030$; these 3.0 points represent a $17 \%$ increase in the fertility rate. Another way to phrase is that this 0.17 figure measures the average semi-elasticity of fertility with respect 


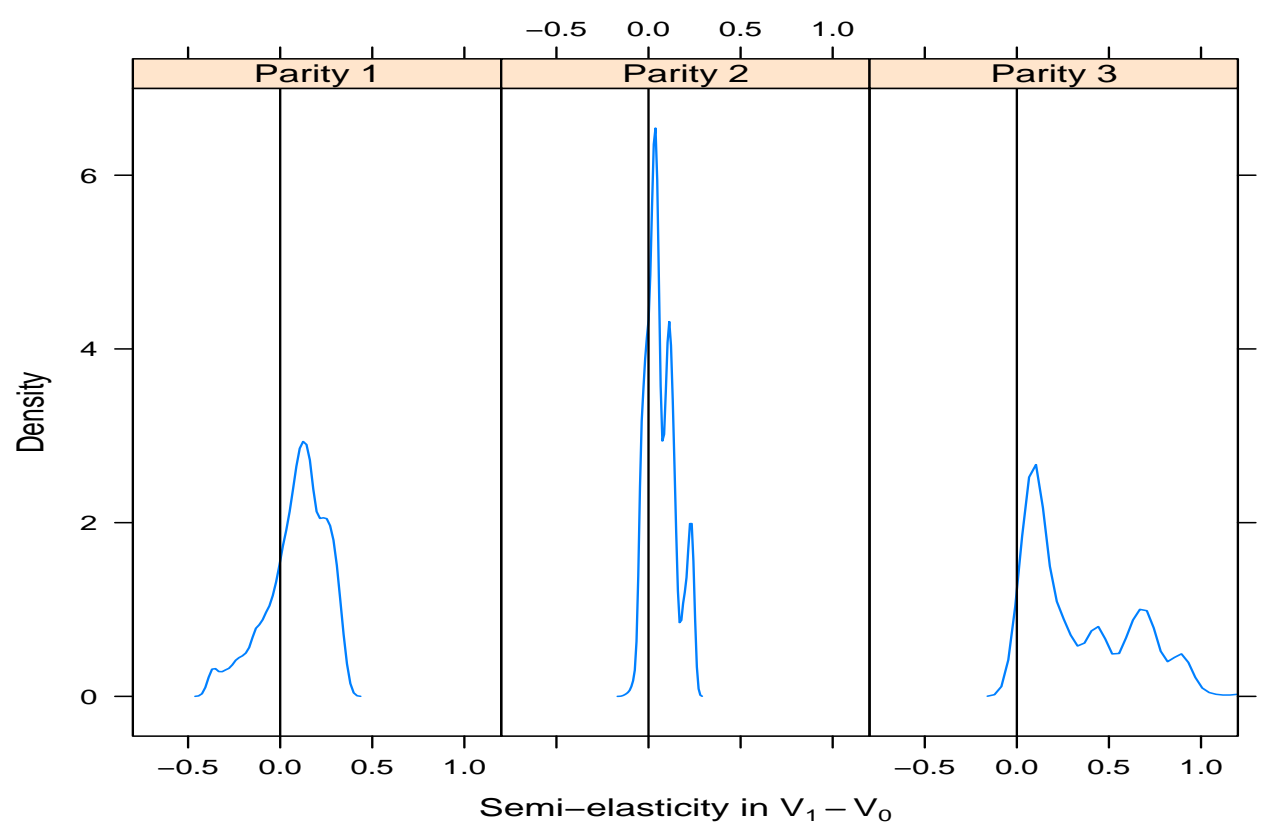

Figure 3: Semi elasticity of the probability of fertility with respect to $V_{1}-V_{0}$

to financial incentives for this group of women:

$$
\frac{\partial \ln Q}{\partial\left(V_{1}-V_{0}\right)}=0.17
$$

Given the very diverse household compositions and incomes, the semielasticities vary a lot in the population. This appears clearly in figure 3, which plots the distribution of the estimated semi-elasticity with respect to $\left(V_{1}-V_{0}\right)$ in our sample ${ }^{15}$. The first striking fact is perhaps that for second births (the middle panel), the estimated semi-elasticities cluster around zero: only $30 \%$ are larger than 0.1 , and $20 \%$ are in fact negative (albeit small). Thus financial incentives seem to play little role in the decision to have a second child.

On the other hand, almost all estimated semi-elasticities are positive for

\footnotetext{
${ }^{15}$ Figures 3, 6, 4 and 5 focus on women of ages 24 to 36 . Only $15 \%$ of first births occur before age 24 , and $15 \%$ of third births occur after age 36 .
} 
the third birth, and half of them are larger than 0.3. These are large effects: according to our estimates, an increase of 100 euros per month would bring the probability of a third birth from 0.08 to 0.11 for a woman with two children at age 32 (which is the median age for a third birth.)

The picture is more mixed for first births, as shown in the left panel of figure 3. At the median age of 28 for a first birth, almost all semi-elasticities are positive, and half of them are above 0.16. The effect is twice larger on average for younger women; on the other hand, it becomes negative for the majority of women of age 30 and older. On the whole population of childless women, $80 \%$ of estimated semi-elasticities are positive; and the median is 0.11 , which is much smaller than for third births.

As the discussion above makes clear, the estimated effects are quite sensitive to age. The profile of the estimated coefficients of financial incentives $\left(V_{1}-V_{0}\right)$ for each age is represented on Figure 4, along with the $95 \%$ confidence band. Other factors also play an important role. Note for instance from Table 8 that childless college graduates seem to be more sensitive to financial incentives than women without a college education. This is partly compensated by the fact that college graduates of course have children later, when the baseline effect turns negative; still, they tend to have a slightly larger semi-elasticity than other women. This is somewhat surprising; and Table 10 confirms it for the third birth.

Our specification also allows for income effects, through the interactions of $V_{0}$ with age, education and family composition. The age profile, keeping fixed education and family composition, is represented on Figure 5. The overall effect on fertility is negative for women with lower education, and close to zero for those with a college education. Figure 6 shows a striking symmetry to Figure 3: for each parity, the estimated densities are close mirror images with respect to the zero vertical line. 


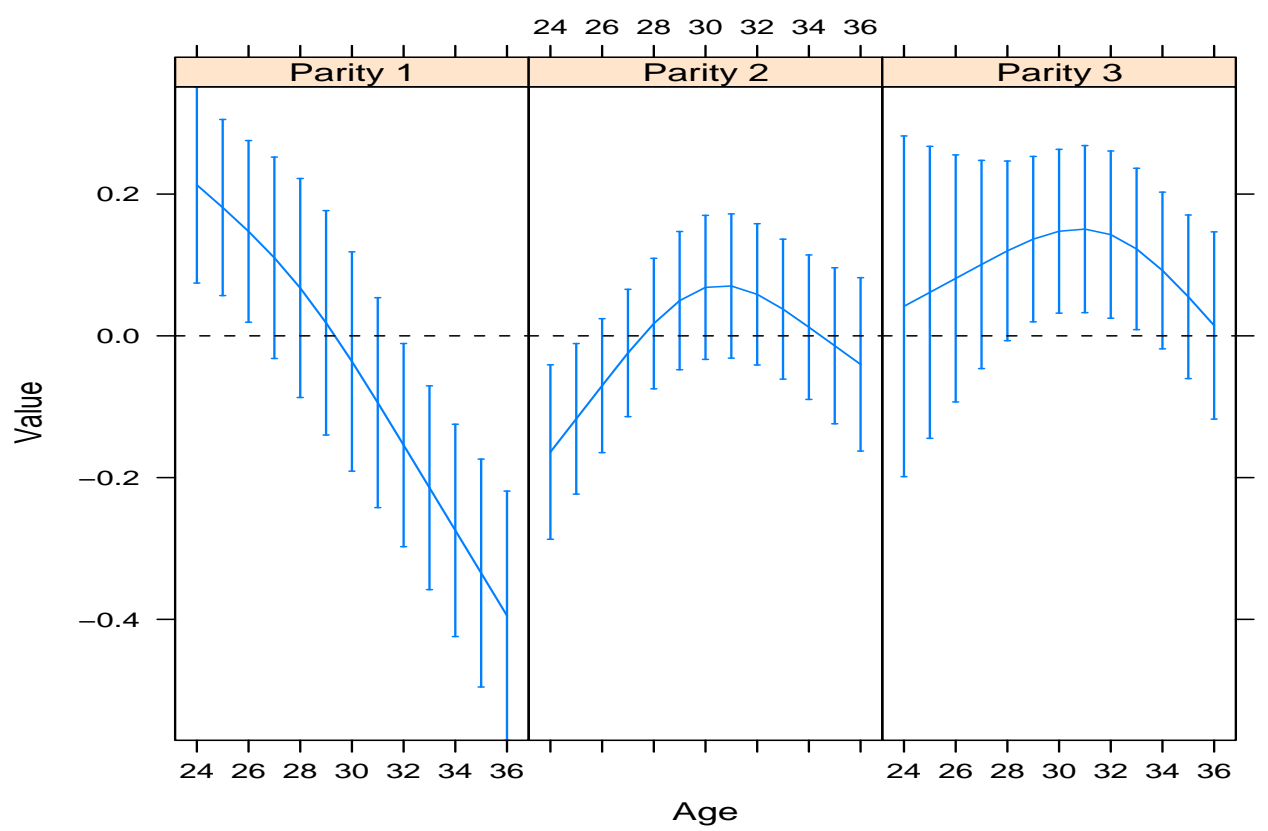

Figure 4: Estimated effects of $\left(V_{1}-V_{0}\right)$ on fertility

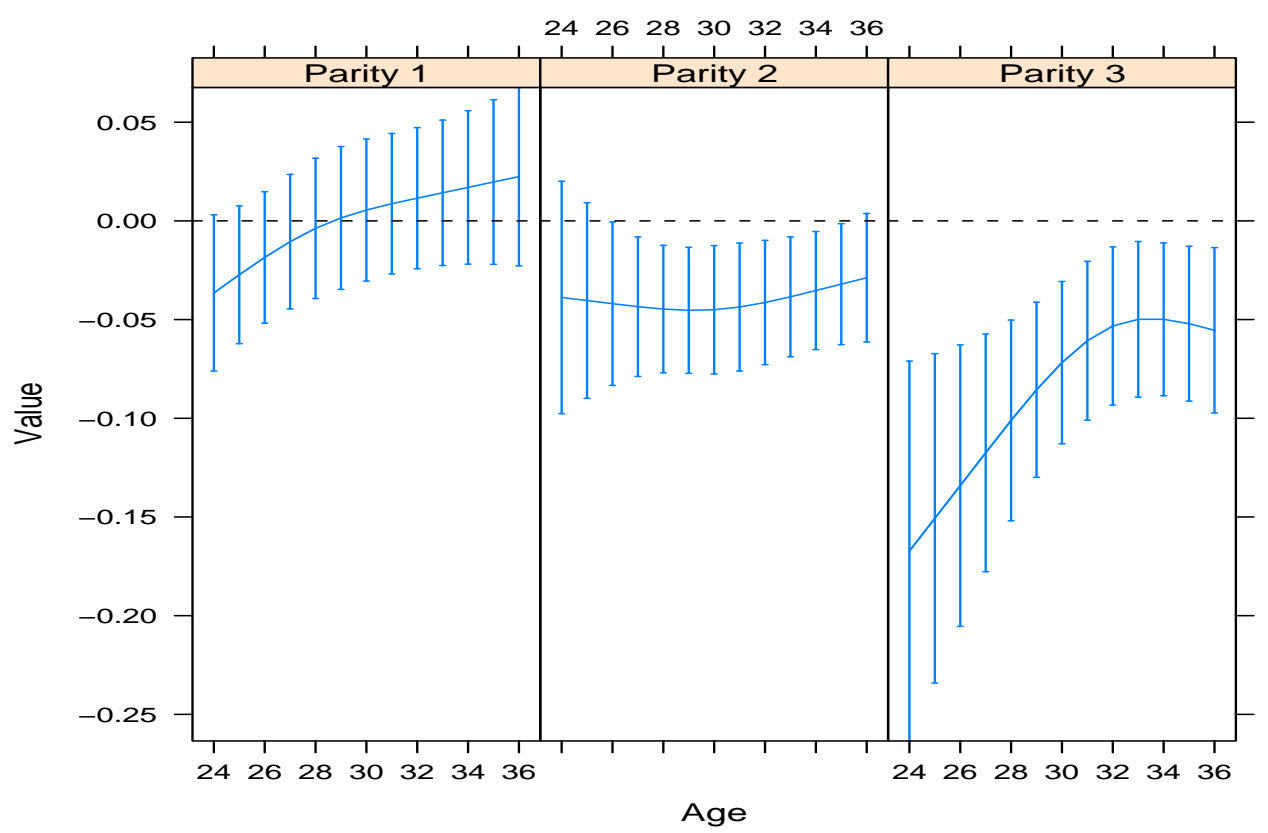

Figure 5: Estimated effects of $V_{0}$ on fertility 


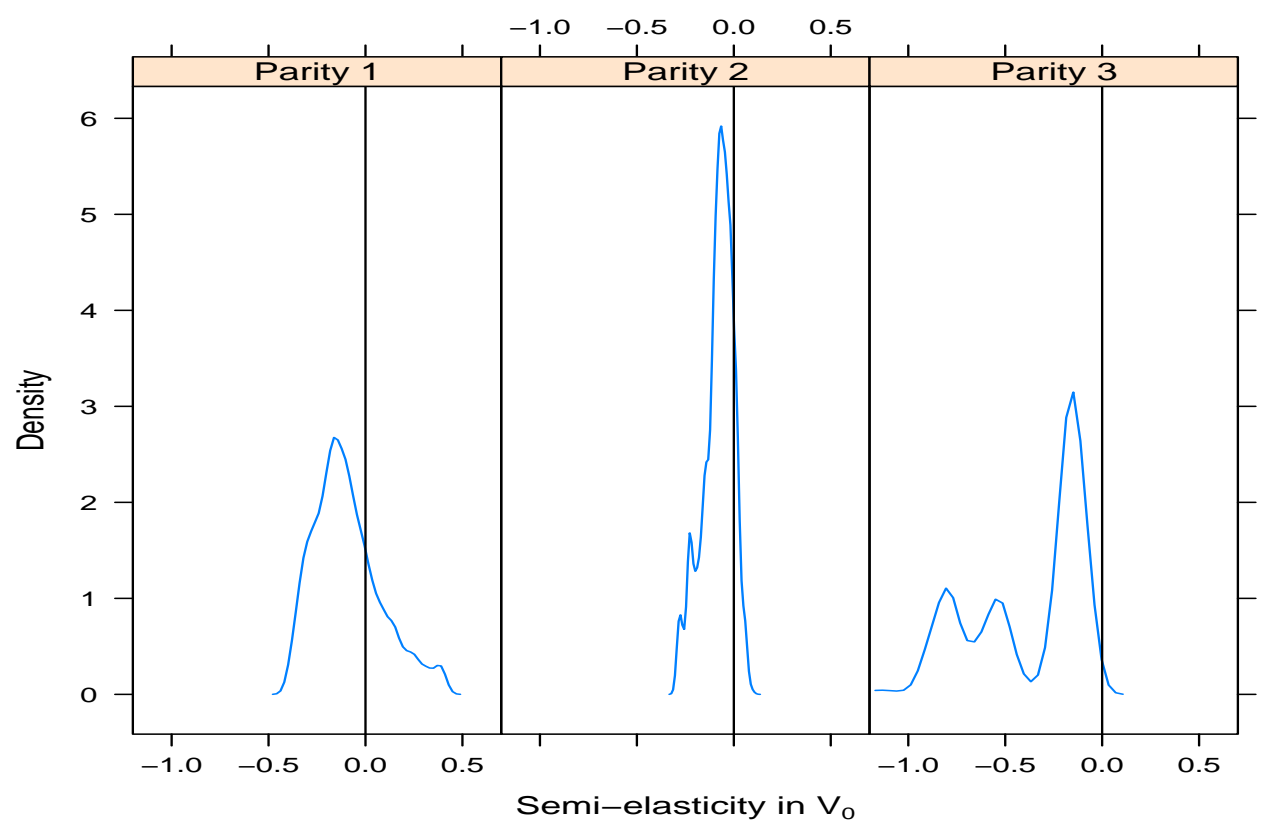

Figure 6: Semi elasticity of the probability of fertility with respect to $V_{0}$

A specification test. We carried out the test described in section 2.3. When we include six $\gamma_{3}$ and $\gamma_{4}$ coefficients (one of each for each of the three parities), the test that they are jointly zero is rejected, with a $p$-value of $1 \%$. However, this is due to parity 2: the null hypothesis is not rejected for parities 1 and 3 .

A quadratic variant. We checked the robustness of the results by estimating a slightly different model, involving a quadratic income term in the utility function:

$$
\tilde{u}_{L F}(R)=u_{L F}(R)+d_{F} R^{2}
$$

We allow the coefficient $d$ to differ according to $F$, as well as to parity. Compared with the reference specification, there are six new coefficients to be estimated. We also modify the normalization to keep close with the initial $V_{F}$ into

$$
\tilde{V}_{F}=\frac{1}{\mu_{F}+d_{F} R_{0 F}} \operatorname{Emax}\left[\tilde{u}_{0 F}, \tilde{u}_{1 F}\right]
$$


The point estimates of all the coefficients are positive, pointing towards a convex utility function. The coefficients are largest for parity 1, smaller for parity 0 , and close to zero for parity 2. While the sum $\mu_{F}+d_{F} R_{0 F}$ stays positive, some of the $\mu_{F}$ coefficients become negative. A likelihood test indicates that the quadratic terms are highly significant: the difference between the two values of the log-likelihood is 19.6, for six degrees of freedom. However we have not pursued this specification as the improvement of the fit concerns labor supply, while the adjustment of fertility deteriorates.

The importance of financial incentives. We estimated the reference model, constraining all the thirty-six coefficients of the value functions $V_{F}$ in the fertility equation to be zero. The log-likelihood is reduced by 86.9 points, which is significant at any level. Thus in statistical terms, financial incentives are highly significant in the fertility decision.

\section{Simulating a child credit}

\begin{tabular}{|r||r|r|r||r|r|r|}
\hline \hline \multicolumn{1}{|c||}{} & \multicolumn{3}{c||}{ Unconditional } & \multicolumn{3}{c|}{ Employment tested } \\
\hline Parity & Fertility & Work & Work/newborn & Fertility & Work & Work/newborn \\
\hline 1 & 2.6 & -0.6 & -1.2 & 1.6 & -1.7 & -7.5 \\
2 & 1.1 & -0.5 & -1.0 & 0.7 & -1.3 & -5.4 \\
3 & 3.0 & -0.5 & -0.9 & 2.5 & -0.8 & -5.1 \\
\hline All & 2.2 & -0.5 & -1.0 & 1.6 & -1.2 & -6.0 \\
\hline
\end{tabular}

Table 3: Changes in fertility and participation associated with a child credit policy

Another way to describe the magnitude of the sensitivity of fertility to financial incentives is to mimic a reform of family benefits. We approximate such a reform by increasing the $R$ 's in case of birth by 150 euros per month. This additional transfer is akin to a universal child subsidy, neither means tested nor employment tested. This would be very costly - about $0.3 \%$ of GDP - and therefore we take it as an upper bound of realistic policy changes. 
We can evaluate the effects of such a reform by adding it to our tax-benefit computation module, simulating its effects on labor supply, recomputing $V_{0}$ and $V_{1}$, and simulating fertility according to the above model. We contrast the situations where the transfer is conditional on stopping work $\left(R_{01}\right.$ is increased by 150 euros, not $R_{11}$ ) or unconditional (both $R_{01}$ and $R_{11}$ are changed). The aggregate results, shown in points of fertility and labor force participation, appear in Table 3, with box-plot graphs of the impacts on Figures 7 and 8 .

The exercise confirms that the effects of financial incentives on fertility are sizeable. The unconditional child credit increases the fertility rate in the sample by 2.2 points, from $15.5 \%$ to $17.7 \%$. The increase is pronounced for the first and third children, smaller for parity 2. It is associated with a modest decrease of .5 point in labor participation, from $49.1 \%$ to $48.6 \%$.

When the child credit is conditioned on not working, the increase in fertility is only 1.6 points, which is still large. The brunt of the reduction bears on first births: indeed women without children have the largest participation rate, $63.1 \%$, to be compared with $47.8 \%$ for women with one child and $37.3 \%$ for women with two children. Unsurprisingly, the overall reduction in participation is larger than when the child credit is unconditional, -1.2 point instead of -0.5. This effect is of course concentrated on women with a newborn, for which it is huge: their participation goes down by 6.0 points $^{16}$.

\section{Conclusion}

Our paper adopts an approach that differs from much of the literature on evaluation. This choice is driven by the specific features of the problem we study. Given that fertility behavior depends so crucially on ages (of parents

\footnotetext{
${ }^{16}$ This is in line with the results found in France after the extension of the Allocation parentale d'éducation to the second born in 1994: its value amounted to 450 euros, and it may have reduced participation of this group by 15 points.
} 


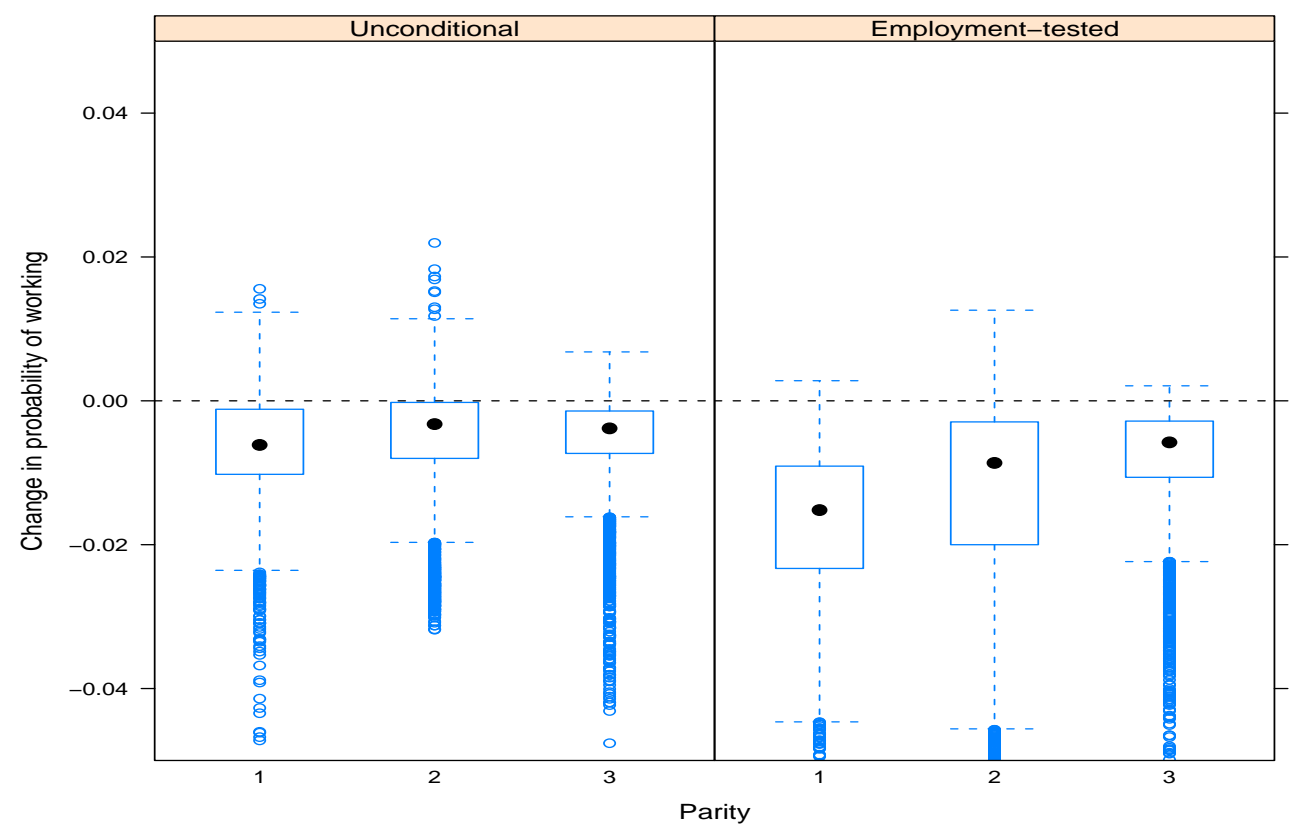

Figure 7: Child credit: impact on labor supply

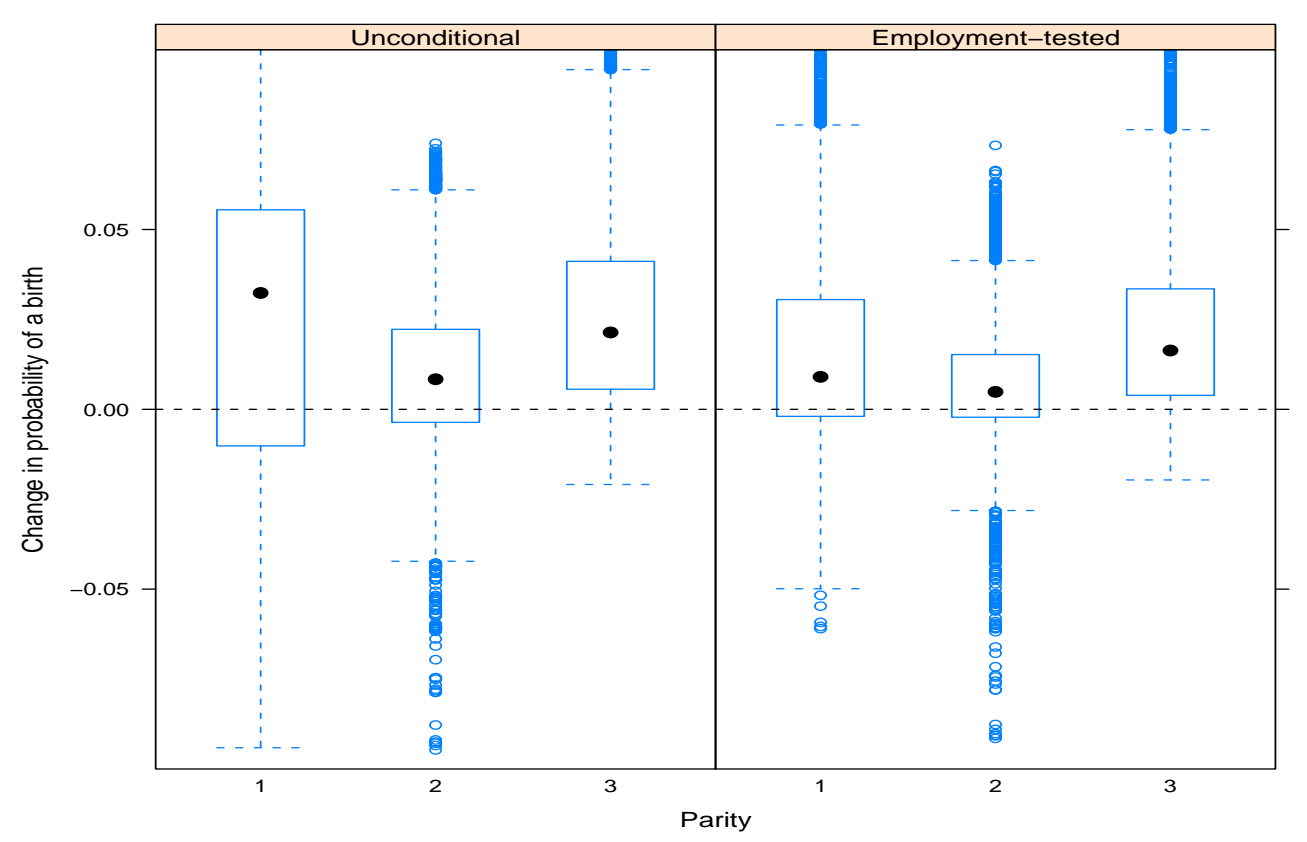

Figure 8: Child credit: impact on fertility 
and of existing children), and that drastic reforms are few and far between, most of the useful variation is to be found on cross section data. It consists of the differences in fertility- and employment-contingent household incomes generated by differences of (potential, conditional) wages and the specificities of the French tax-benefit system. Nonlinearities of tax-benefit schemes have been much used to study labor supply, see e.g. Blundell, Duncan, and Meghir (1998) and Laroque and Salanié (2002). Indeed, these variations are sufficient to nonparametrically identify labor supply behavior; but they are not enough to identify the joint labor supply and fertility decisions. We therefore introduce an additional assumption, which states that labor supply shocks, conditional on realized fertility, are independent of the fertility shock. The implied separability of the functional form can be tested along lines similar to Ichimura and Taber (2002).

This orthogonality assumption is natural here, since the fertility decision usually takes place about one year before the conditional choice of labor supply. It yields a nonparametric generalization of the nested logit specification; this may be useful in other applications where the conditional independence assumption is economically reasonable. As an example, work in progress by Chiappori, Salanié, Tillman and Weiss uses a similar approach to examine endogamy by ethnic group and education level.

In order to reduce the incidence of possible unobserved "taste for children" factors, we used a very detailed specification by age and parity. The overall procedure appears to work well and to yield robust results. Fertility is quite sensitive to financial incentives for the first and the third birth, but it hardly responds to them for the second birth. 


\section{References}

Apps, P., And R. Rees (2004): "Fertility, Female Labour Supply and Public Policy," Scandinavian Journal of Economics, 106, 745-763.

Becker, G. (1960): "An Economic Analysis of Fertility," in Demographic and Economic Change in Developed Countries. NBER.

— (1991): A Treatise on the Family. Harvard University Press.

Besley, T., And A. Case (2000): "Unnatural Experiments? Estimating the Incidence of Endogenous Policies," Economic Journal, 110, F672-F694.

Blanchet, D., and O. Ekert-Jaffé (1994): "The Demographic Impact of Family Benefits: Evidence from a Micromodel and from Macrodata," in The Family, the Market and the State in Ageing Societies, ed. by J. Ermisch, and N. Ogawa. Clarendon Press.

Blau, D., And P. Robins (1989): "Fertility, Employment, and Child-care Costs," Demography, 26, 287-299.

Blundell, R., A. Duncan, and C. Meghir (1998): "Estimating Labor Supply Responses Using Tax Reforms," Econometrica, 66, 827-861.

Choné, P., D. Leblanc, and I. Robert-Bobée (2004): "Offre de travail féminine et garde des enfants," Economie et prévision, 162.

Cigno, A. (1986): "Fertility and the Tax-Benefit System: A Reconsideration of the Theory of Family Taxation," Economic Journal, 96, 1035-1051.

Cohen, A., R. Dehejia, and D. Romanov (2007): "Do Financial Incentives Affect Fertility?," Discussion Paper 13700, NBER.

Del BocA, D. (2002): "The Effect of Child Care and Part-time Opportunities on Participation and Fertility Decisions in Italy," Journal of Population Economics, 15, 549-573.

EkerT-JAFFÉ, O. (1986): "Effets et limites des aides financières aux familles : une expérience, un modèle," Population, 2, 327-348. 
Gauthier, A. (1996): The State and the Family. Oxford University Press.

Gauthier, A., And J. Hatzius (1997): "Family Benefits and Fertility: An Econometric Model," Population Studies, 51, 295-346.

HeCKman, J. (1976): "Simultaneous Equation Models with Continuous and Discrete Endogenous Variables and Structural Shifts," in Studies in Nonlinear Estimation, ed. by S. Goldfeld, and R. Quandt. North Holland.

Heckman, J., and J. Walker (1989): "Using Goodness of Fit and Other Criteria to Choose among Competing Duration Models: A Case Study of Hutterite Data," in Sociological Methodology, ed. by C. Clogg. American Sociological Association.

(1990a): "The Relationship between Wages and Income and the Timing and Spacing of Births: Evidence from Swedish Longitudinal Data," Econometrica, 58, 1411-1441.

- (1990b): "The Third Birth in Sweden," Journal of Population Economics, 3, 235-275.

Hotz, J., R. Klerman, and R. Willis (1997): "The Economics of Fertility in Developed Countries," in Handbook of Population Economics, ed. by M. Rosenzweig, and O. Stark. North Holland.

Hotz, J., And R. Miller (1988): "An Empirical Model of Lifecycle Fertility and Female Labour Supply," Econometrica, 56, 91-118.

Hume, D. (1776 (2005)): Dialogues Concerning Natural Religion. Barnes and Noble.

ICHimura, H., And C. TABer (2002): "Semiparametric Reduced-Form Estimation of Tuition Subsidies," American Economic Review, 92, 286-292.

Keane, M., And K. Wolpin (2007a): "Exploring the Usefulness of a Nonrandom Holdout Sample for Model Validation: Welfare Effects on Female Behavior," International Economic Review, 48, 1351-1378. 
(2007b): "The Role of Labor and Marriage Markets, Preference Heterogeneity and the Welfare System on the Life Cycle Decisions of Black, Hispanic and White Women," Discussion paper, University of Pennsylvania.

Kearney, M. S. (2004): "Is There an Effect of Incremental Welfare Benefits on Fertility Behavior? A Look at the Family Cap," Journal of Human Resources, 39, 295-325.

Laroque, G., and B. Salanié (2002): "Labor Market Institutions and Employment in France," Journal of Applied Econometrics, 17, 25-48.

- (2004a): "Fécondité et offre de travail des femmes en France," Économie publique, 13(2), 61-94.

(2004b): "Fertility and Financial Incentives in France," CESIfo Economic Studies, 50, 423-450.

Lefebvre, P., L. Brouillette, and C. Felteau (1994): "Les effets des impôts et des allocations familiales sur les comportements de fécondité et de travail des canadiennes : résultat d'un modèle de choix discrets," Population, 2, 415-456.

Milligan, K. (2004): "Subsidizing the Stork: New Evidence on Tax Incentives and Fertility," Review of Economics and Statistics, forthcoming.

Moffitt, R. (1998): "The Effect of Welfare on Marriage and Fertility," in Welfare, the Family, and Reproductive Behavior: Research Perspectives, ed. by R. Moffitt. National Academy Press.

Piketty, T. (2005): "L'impact de l'allocation parentale d'éducation sur l'activité féminine et la fécondité en France, 1982-2002," in Histoires de familles, histoires familiales, ed. by C. Lefèvre. INED.

Rosenzweig, M. (1999): "Welfare, Marital Prospects, and Nonmarital Childbearing," Journal of Political Economy, 107, S3-S32. 


\begin{tabular}{|r|r|r|}
\hline \multicolumn{3}{|c|}{ Wage equation } \\
\hline variable & estimate & std error \\
\hline Age at end of study & 0.140 & 0.014 \\
id. squared & -2.617 & 0.325 \\
Time since end of study & 0.047 & 0.003 \\
id. squared & -0.843 & 0.124 \\
Diploma 1 & 0.696 & 0.019 \\
Diploma 2 & 0.476 & 0.016 \\
Diploma 3 & 0.305 & 0.014 \\
Diploma 4 & 0.166 & 0.012 \\
Diploma 5 & 0.154 & 0.016 \\
1997 survey & 7.008 & 0.144 \\
1998 survey & 7.001 & 0.144 \\
1999 survey & 6.988 & 0.144 \\
\hline$\sigma$ & 0.265 & 0.003 \\
\hline
\end{tabular}

Table 4: The wage equation

Rosenzweig, M., and T. P. Schultz (1985): "The Demand for and Supply of Births: Fertility and its Lifecycle Consequences," American Economic Review, 75, 992-1015.

WiLlis, R. (1973): "A New Approach to the Economic Theory of Fertility Behavior," Journal of Political Economy, 81, S14-S64.

\section{Appendix}

The estimation results for the wage equation appear in Table 4. They are very similar to those in our earlier papers and book. 


\begin{tabular}{|c|r|r|}
\hline \multicolumn{3}{|c|}{$\mu_{0}$} \\
\hline Variable & estimate & std error \\
\hline $20-22$ & .29 & .10 \\
23 & .21 & .05 \\
24 & .30 & .04 \\
25 & .26 & .03 \\
26 & .24 & .03 \\
27 & .26 & .03 \\
28 & .22 & .02 \\
Age 29 & .23 & .02 \\
30 & .21 & .02 \\
31 & .18 & .02 \\
32 & .22 & .02 \\
33 & .22 & .02 \\
34 & .19 & .02 \\
35 & .20 & .02 \\
36 & .18 & .02 \\
37 & .20 & .02 \\
38 & .19 & .02 \\
39 & .22 & .02 \\
College & -.04 & .01 \\
Parity 2 & -.01 & .01 \\
Parity 3 & -.04 & .01 \\
\hline
\end{tabular}

Table 5: The coefficients of financial incentives in labor supply

\begin{tabular}{|l|r|r|}
\hline \multicolumn{3}{|c|}{$\nu_{0}$} \\
\hline Variable & estimate & std error \\
\hline Constant & -.06 & .01 \\
Child aged 1 & .01 & .01 \\
Child aged 2 & .02 & .01 \\
Parity 2 & .00 & 0.01 \\
Parity 3 & .03 & 0.01 \\
\hline
\end{tabular}

$$
\nu_{1}=\nu_{0}+\underset{(.02)}{.07}+\underset{(.02)}{.15} \mathbb{1} \text { Parity } 3
$$

Table 6: Income effects in labor supply 


\begin{tabular}{|r|r|r|}
\hline \multicolumn{3}{|c|}{$\pi_{0}$} \\
\hline Variable & estimate & std error \\
\hline $20-22$ & -1.34 & .31 \\
23 & -.88 & .23 \\
24 & -.74 & .22 \\
25 & -.88 & .21 \\
26 & -.52 & .18 \\
27 & -.57 & .16 \\
28 & -.40 & .16 \\
Age 29 & -.20 & .15 \\
30 & -.47 & .16 \\
31 & -.50 & .16 \\
32 & -.27 & .16 \\
33 & -.30 & .16 \\
34 & -.21 & .14 \\
35 & -.36 & .15 \\
36 & -.47 & .15 \\
37 & -.71 & .17 \\
38 & .05 & .01 \\
39 & -.04 & .02 \\
Unmarried & -0.71 & 0.32 \\
\hline
\end{tabular}

$\pi_{1}=\pi_{0}-\underset{(1.88)}{3.58-\underset{(0.07)}{0.04} \mathbb{1}}$ College $\underset{(0.32)}{-0.471}$ Parity $3_{(0.06)}^{-0.22 \mathbb{1}}$ Unmarried $_{(0.12)}^{+0.15}$ Age- $\underset{(0.18)}{0.12} \frac{\text { Age squared }}{100}$

Table 7: Constant terms in labor supply 


\begin{tabular}{|l|r|r|}
\hline \hline \multicolumn{1}{|c|}{ Variable } & Estimate & Standard Error \\
\hline$\Delta V$, age 24 & .21 & .07 \\
$\Delta V$, age 28 & .07 & .08 \\
$\Delta V$, age 32 & -.15 & .07 \\
$V_{0}$, age 24 & -.04 & .02 \\
$V_{0}$, age 28 & -.00 & .02 \\
$V_{0}$, age 32 & .01 & .02 \\
$\Delta V$, college graduate & .17 & .08 \\
$V_{0}$, college graduate & .00 & .02 \\
\hline age 24 & -.36 & .28 \\
age 28 & -.71 & .30 \\
age 32 & -.97 & .34 \\
unmarried & -.47 & .65 \\
unmarried $\times$ age & -.01 & .02 \\
college graduate & -2.50 & .86 \\
college graduate $\times$ age & .08 & .03 \\
\hline
\end{tabular}

Table 8: Fertility Effects for First Birth 


\begin{tabular}{|l|r|r|}
\hline \hline \multicolumn{1}{|c|}{ Variable } & Estimate & Standard Error \\
\hline$\Delta V$, age 26 & -.07 & .05 \\
$\Delta V$, age 30 & .07 & .05 \\
$\Delta V$, age 34 & .01 & .05 \\
$V_{0}$, age 26 & -.04 & .02 \\
$V_{0}$, age 30 & -.05 & .02 \\
$V_{0}$, age 34 & -.04 & .02 \\
$\Delta V$, college graduate & .00 & .06 \\
$V_{0}$, college graduate & .05 & .02 \\
$\Delta V$ first born is 1 & .19 & .09 \\
$\Delta V$ first born is 2 & .10 & .06 \\
$\Delta V$ first born is 3 & .13 & .06 \\
$V_{0}$ first born is 1 & .00 & .02 \\
$V_{0}$ first born is 2 & .01 & .02 \\
$V_{0}$ first born is 3 & .01 & .02 \\
\hline age 26 & .15 & .35 \\
age 30 & -.67 & .31 \\
age 34 & -1.50 & .33 \\
unmarried & -2.76 & .61 \\
unmarried $\times$ age & .08 & .02 \\
college graduate & -1.62 & .89 \\
college graduate $\times$ age & .03 & .03 \\
first born is 1 & -2.30 & .48 \\
first born is 2 & -.68 & .34 \\
first born is 3 & .91 & .36 \\
first born is 4 & .65 & .13 \\
first born is 5 & .21 & .15 \\
first born is 6 & & .17 \\
\hline
\end{tabular}

Table 9: Fertility Effects for Second Birth 


\begin{tabular}{|l|r|r|}
\hline \hline \multicolumn{1}{|c|}{ Variable } & Estimate & Standard Error \\
\hline$\Delta V$, age 27 & .10 & .07 \\
$\Delta V$, age 32 & .14 & .06 \\
$\Delta V$, age 36 & .01 & .07 \\
$V_{0}$, age 27 & -.12 & .03 \\
$V_{0}$, age 32 & -.05 & .02 \\
$V_{0}$, age 36 & -.06 & .02 \\
$\Delta V$, college graduate & .18 & .10 \\
$V_{0}$, college graduate & .09 & .02 \\
$\Delta V$ one child is 1 & .60 & .54 \\
$\Delta V$ one child is 2 & .35 & .30 \\
$\Delta V$ one child is 3 & -.02 & .07 \\
$V_{0}$ one child is 1 & -.01 & .04 \\
$V_{0}$ one child is 2 & -.03 & .02 \\
$V_{0}$ one child is 3 & -.01 & .02 \\
\hline age 27 & -.44 & .61 \\
age 32 & -2.35 & .50 \\
age 36 & -2.49 & .51 \\
unmarried & -4.28 & .99 \\
unmarried $\times$ age & -.14 & .03 \\
college graduate & -.11 & 1.74 \\
college graduate $\times$ age & -.05 & .05 \\
one child is 1 & -2.05 & .29 \\
one child is 2 & .31 & .62 \\
one child is 3 & .31 & .50 \\
one child is 4 & .41 & .18 \\
one child is 5 & .30 & .18 \\
one child is 6 & & .20 \\
children between 7 and 10 & \\
\hline
\end{tabular}

Table 10: Fertility Effects for Third Birth 